\title{
Pluriatividade e política pública: o caso do Sul do Brasil
}

\section{CARLOS ALVES DO NASCIMENTO*}

Pluriactivity and public policy: the case of the South of Brazil. The growth of contingent of pluriactive farm families (pluriactivity) has increasingly been accepted as important in reducing rural poverty and unemployment since at least two decades in the EU and very recently in Brazil. This paper supports that, differently from the EU, in the South Brazil, region of modern capitalist agriculture, it is hard to the pluriactivity to grow through the years, and in order for it to increase the public policies, it must be led mainly to avoid the exclusion of the small farms, their gradual abandonment of the traditional agricultural activities, and not only to offer them non agricultural occupations.

Key-words: Pluriactivity; farm families; public policies.

JEL Classification: R23.

\section{INTRODUÇÃO}

Face à crise urbano-industrial contemporânea, instituições e governos de países desenvolvidos passaram a compreender que políticas voltadas para o meio rural podem surtir reflexos positivos sobre o meio urbano (Grupo de Brugge, 1996).

Nesse contexto, a pluriatividade ${ }^{1}$ das famílias rurais passou a ser vista como uma forte aliada no esforço de resolução dos dilemas comuns às áreas urbana e rural. A pluriatividade significaria, principalmente para muitos agricultores familiares descapitalizados e não integrados às cadeias agroindustriais, uma importante alternativa de reprodução social, garantindo a esse contingente uma maior estabilidade diante das incertezas do mercado de trabalho.

\footnotetext{
* Professor Adjunto do IE/UFU - Instituo de Economia da Universidade Federal de Uberlândia, Campus Santa Mônica, Av. João Naves de Ávila, 2121, Uberlândia, MG. E-mail: can@ie.ufu.br. Submetido: março 2006; aceito: julho 2006.

${ }^{1}$ Famílias rurais que conciliam, entre seus membros, atividades agrícolas e atividades não agrícolas (no interior ou fora do estabelecimento).
} 
Nesses termos, a importância da pluriatividade tem sido reconhecida, há muito, pelas autoridades políticas e econômicas da União Européia (UE), em virtude da sua histórica preocupação em preservar a sua estrutura agrária baseada na agricultura familiar (Tolosana e Persiva, 1992). No Brasil, ao contrário, a pluriatividade só tem encontrado relativa importância entre alguns pesquisadores acadêmicos que se interessam pelo tema ${ }^{2}$ (Campanhola e Graziano da Silva, 2000; Sacco dos Anjos, 2003; Schneider, 2003; Nascimento, 2005b).

$\mathrm{Na}$ UE, o crescimento da pluriatividade é, a nosso juízo, claramente o resultado de uma construção política, no sentido de que sua Política Agrícola Comum (PAC) criou as condições necessárias para a configuração e sustentação de uma verdadeira "cultura da pluriatividade" (Nascimento, 2005a).

No Brasil, nas décadas de 1960, 1970 e 1980, a política agrícola de modernização da agricultura, conduzida pelo Sistema Nacional de Crédito Rural (SNCR), privilegiou a grande propriedade como centro do modelo agrícola a ser estruturado no país. Em virtude disso, excluiu do seu raio de cobertura milhares de pequenos produtores familiares. Só recentemente, em meados dos anos 1990, o Ministério do Desenvolvimento Agrário (MDA) elegeu, através da criação do Programa Nacional de Fortalecimento da Agricultura Familiar (PRONAF), a agricultura familiar como a base social sobre a qual se pretende implementar um novo modelo de desenvolvimento rural no país (Aquino et al., 2000). Contudo, diferentemente da PAC da UE, o PRONAF não teve, desde a sua origem, o intuito de atingir todos os segmentos de agricultores familiares existentes no país, deixando de lado os estabelecimentos classificados como periféricos (Aquino et al., 2004). Além disso, mesmo para aqueles que são o seu público-alvo (os em transição e os consolidados), o Programa ainda não tem sido bem-sucedido em atingir a todos, e sim apenas a uma pequena parte deles (Bittencourt, 2003).

Assim, a pretensa base social de um novo modelo de desenvolvimento rural para o Brasil fica cindida entre famílias de agricultores viáveis e famílias de agricultores inviáveis - do ponto de vista do mercado. O PRONAF se encarregaria dos primeiros e a pluriatividade poderia vir a ser — segundo a óptica acadêmica — um instrumento de apoio para ambos os segmentos.

Entretanto, a questão que julgamos central é: os problemas sociais (rurais e urbanos) — os quais a pluriatividade poderá colaborar no esforço para sua reso-

\footnotetext{
${ }^{2}$ Não obstante essa discussão ainda seja recente no Brasil, cabe lembrar aqui que o referido debate já começou, muito recentemente, a encontrar espaço em certas instituições públicas oficiais do país. Exemplo disso é que o Ministério do Desenvolvimento Agrário (MDA), junto com o Conselho Nacional de Desenvolvimento Rural Sustentável (CONDRAF), realizaram em Brasília, nos dias 23 a 25 de agosto de 2005, o Seminário Nacional de Desenvolvimento Rural Sustentável, que tinha como um dos painéis principais "O papel da pluriatividade numa estratégia de desenvolvimento rural". No presente artigo, todavia, defendemos que os "caminhos" (de políticas públicas) propostos para promover pluriatividade - basicamente o fomento a atividades não agrícolas — não necessariamente redundarão nesse objetivo, uma vez que a pluriatividade fica desfocada do seu ponto mais crítico, conforme buscaremos mostrar ao longo do texto.
} 
lução — são crescentes e, portanto, para a pluriatividade cumprir a função a ela atribuída, deverá acompanhar esse crescimento. É incoerente, então, esperar que a pluriatividade contribua para reduzir o desemprego rural e amenizar o drama social dele decorrente se ela apresentar um crescimento nulo ou negativo - contrário à trajetória dos problemas que deve enfrentar. Dessa forma, a pluriatividade só servirá para um contingente de famílias rurais progressivamente reduzido, resultado que frustrará as expectativas em relação a ela.

Assim sendo, para inferir se a pluriatividade está cumprindo sua função de forma crescente no seio da agricultura familiar, escolhemos acompanhar sua evolução na região Sul por duas razões: por ser a segunda maior detentora da agricultura familiar nacional; ${ }^{3}$ e por ser onde estariam reunidas - na opinião de Sacco dos Anjos (2003) e Schneider (2003) - as melhores condições para o crescimento da pluriatividade (especialmente a intersetorial). ${ }^{4}$

A pluriatividade é um fenômeno social presente em todo o território nacional. No entanto, para abordá-la inserida na questão mais ampla de um esforço nacional de implementação de um novo modelo de desenvolvimento rural para o país, faz-se necessário conhecer sua dinâmica em termos de tendência (evolução) com vistas a subsidiar futuras (opções de) políticas públicas para o rural. Somente nesses termos ganha sentido a discussão que ora nos propomos fazer sobre a possibilidade de crescimento da pluriatividade no Sul. Entendemos que seu crescimento não é um resultado automático decorrente de transformações em economias locais provocadas pelo progresso técnico e da reação das famílias rurais a tais transformações.

A nosso ver, somente o elemento político (políticas públicas) é capaz de explicar a razão de hoje se poder considerar que existe uma trajetória de crescimento da pluriatividade na UE. Ali o Estado foi capaz de construi-la ao defender milhares de pequenos agricultores familiares (“inviáveis" para o mercado) dos efeitos adversos provocados pelo avanço das relações capitalistas sobre a agricultura daquele continente. $^{5}$

No presente artigo, apresentamos as razões que nos autorizam a defender que as condições reunidas pela região Sul do Brasil são propícias não para o crescimento da pluriatividade - conforme sugerem Sacco dos Anjos (2003) e Schnei$\operatorname{der}(2003)$ - , senão para dificultar o seu crescimento, especialmente em se tratando da pluriatividade intersetorial.

\footnotetext{
${ }^{3}$ O Nordeste é a primeira. Juntos, Nordeste e Sul, abrigam praticamente $80,0 \%$ da agricultura familiar nacional.

${ }^{4}$ A pluriatividade intersetorial é aquela em que a família tem pelo menos um membro ocupado em uma atividade agrícola e pelo menos outro ocupado em uma atividade não agrícola. Já a pluriatividade tradicional consiste na família de conta-própria agrícola, em que pelo menos um membro se assalaria em outro estabelecimento agrícola.

${ }^{5}$ Em Nascimento (2005a) encontram-se todas as referências bibliográficas de autores europeus que sustentam essa argumentação. No presente artigo nos limitamos a citar esse trabalho, de modo a aproveitar o melhor possível o espaço reservado ao objeto central do artigo, que é o Sul do Brasil.
} 
Além desta introdução, o artigo está organizado em mais três seções. A primeira seção apresenta uma análise dos dados referentes à evolução quantitativa dos diferentes tipos de famílias aqui abordados, para o período 1992-1999. A segunda seção atualiza os dados da seção anterior, para o período recente (20012004), cuja análise aponta para a confirmação de nossa hipótese de que a pluriatividade no Sul do Brasil encontra dificuldade para crescer. Na última seção serão feitas as considerações finais.

Antes de avançar, cabe dizer que os dados com os quais trabalhamos são resultados do processamento dos microdados das PNADs/IBGE. Os tipos de famílias são classificados pela posição na ocupação dos membros da família (empregador, conta-própria, assalariado, não ocupado) e, em seguida, pelo ramo de atividade em que estão inseridos (agrícola, não agrícola, pluriativo). ${ }^{6}$ Daremos especial atenção às famílias de conta-própria pluriativas intersetoriais, em razão da importância das ocupações rurais não agrícolas para as famílias agrícolas que se tornam pluriativas (Projeto Rurbano/IE/Unicamp).

As análises seguintes ficarão restritas ao conjunto de famílias "conta-próprias" e "assalariados" residentes nas áreas rurais não metropolitanas denominadas rural agropecuária. ${ }^{8}$ Justifica-se isso pelo fato de que na região Sul todos os tipos de famílias definidas pela posição na ocupação declararam residência, em sua grande maioria (uma média que varia entre $73,0 \%$ e 78,0\%), nas áreas não metropolitanas. Foi nas áreas rurais agropecuárias que se concentraram os tipos de famílias rurais sulinas (variando a proporção entre $80,0 \%$ e $94,0 \%$ ). A maior concentração de famílias residentes nas áreas rurais agropecuárias é das famílias conta-próprias e assalariadas (juntas, perfazem 80,0\% do total), em 2004.

Considera-se como o universo da agricultura familiar a soma dos tipos de famílias de "empregadores com até 2 empregados" e de "conta-próprias" — ambos agrícolas e pluriativos. No entanto, no presente trabalho nosso universo identificado com a agricultura familiar restringe-se ao conjunto de famílias contapróprias. A discussão posteriormente realizada não ficará comprometida, já que o percentual de famílias de "empregadores com até 2 empregados" sobre o total ("empregador com até 2 empregados" mais "conta-próprias") corresponde a

\footnotetext{
${ }^{6}$ Se numa família de conta-próprias houver um membro ocupado na agricultura e nenhum outro fora da agricultura, essa família é classificada como de conta-própria agrícola. Caso a referida família tenha um membro na atividade agrícola e pelo menos um outro ocupado em outro setor, essa é uma família de conta-própria pluriativa. Se o caso for de um membro ocupado fora da agricultura e nenhum outro na agricultura, essa é uma família de conta-própria não agrícola. As mesmas combinações podem ser repetidas para as famílias de assalariados.

${ }^{7}$ Se na família não houver nenhum empregador, mas pelo menos um conta-própria, a família é compreendida como de conta-própria. Na ausência de empregador e de conta-própria, a família será considerada de assalariados caso algum membro esteja ocupado na semana de referência da PNAD como tal.

${ }^{8}$ A idéia de separar o rural agropecuário é tentar reconstruir os espaços considerados predominantemente agrícolas, que são por excelência espaços apropriados por um único dono (público ou privado).
} 
$7,0 \%$. O que equivale a dizer que o percentual de famílias conta-próprias sulinas no universo da agricultura familiar é superior a 90,0\%, um contingente altamente representativo das análises realizadas.

\section{A MODERNIZAÇÃO EXCLUDENTE DA AGRICULTURA NA REGIÃO SUL: PANO DE FUNDO PARA A ANÁLISE DOS DADOS}

Ao analisar a trajetória das famílias sulinas na década de 1990, Nascimento (2005b) mostrou que a contínua redução do número de famílias pluriativas na região Sul estava associada: i) ao fato de a agricultura moderna predominante na região Sul ser excludente; ii) à existência de entornos rurais dinâmicos que favorecem, em combinação com o item anterior, não o crescimento do número de famílias pluriativas, mas de famílias não agrícolas; iii) à maior inserção internacional da economia - abertura comercial com câmbio valorizado - que acirrou a concorrência enfrentada pelos produtores rurais de um modo geral; iv) à paulatina substituição relativa do Estado pelo mercado na organização do setor agrícola; e v) à ação muito tímida do Estado (políticas públicas), compensando as perdas dos pequenos produtores alijados da inserção no mercado.

Enfatizamos aqui apenas o ponto da predominância de uma agricultura moderna excludente na região Sul, em virtude de o considerarmos essencial para o entendimento da dificuldade que a pluriatividade tem para crescer nessa região. A questão central é que a lógica imanente a essa agricultura expressa-se em dois movimentos contraditórios entre si: um, de contínua exigência para que os produtores agrícolas introduzam modernas tecnologias (que não são baratas); outro, marcado pela exclusão, do mercado, daquela parcela de pequenos produtores familiares que não conseguem atender a tais exigências. Esse é "o" elemento fundamental que, na presença dos demais fatores — listados acima -, dificulta o crescimento da pluriatividade, especialmente a intersetorial, na região Sul.

Não obstante o processo de modernização conservadora da agricultura brasileira - assentado na busca desenfreada de elevação da produtividade - ter criado, como uma de suas conseqüências, certas condições ${ }^{9}$ para a proliferação da pluriatividade, por outro lado, foram criadas também, paralelamente, as condições para a retração contínua da pluriatividade na região Sul ao longo do tempo. Para se entender essa nossa afirmação, cumpre recordar que a modernização conservadora da agricultura no Brasil, nos anos 60 e 70, cumpria um duplo objetivo. Por um lado, atender às necessidades internas do desenvolvimento capitalista (aumentar a oferta de matérias-primas, mão-de-obra e alimentos para o mercado interno); e servir como mercado para a indústria produtora de insumos, máquinas e implementos. Por outro lado, reforçava o seu desiderato histórico de

\footnotetext{
${ }^{9}$ Elevação da produtividade das explorações, liberando mão-de-obra familiar para se ocupar em outros setores.
} 
ser o setor com grande peso no financiamento das necessidades nacionais de importação.

Isso significa dizer que a agricultura, no Brasil, jamais foi vista pelas políticas públicas destinadas a ela como um espaço também daqueles produtores que não têm a capacidade de se moldar às exigências de produtividade e fazer frente aos desígnios históricos do setor. Para esse segmento de produtores que não conseguem atingir o perfil do "verdadeiro agricultor", resta se ocupar plenamente em ocupações rurais não agrícolas, ou continuar marginalizados na sua relação com a terra.

Em outras palavras, esse modelo agrícola não assegura a reprodução social, simultaneamente, para ambas as partes envolvidas (de um lado, a agricultura patronal - juntamente com a pequena parcela de agricultores familiares "consolidados", acoplados às agroindústrias; de outro, a massa de "condenados ao atraso") por ser um modelo sobre o qual o Estado, em nenhum momento da história do país, interferiu para apoiar aquela enorme parcela de agricultores "atrasados", de modo que sua reprodução ficou comprometida e reservada para uma fração menor de agricultores (convertidos pelas políticas públicas em) competitivos. Trata-se de um modelo dentro do qual somente têm assegurado sua permanência os produtores que conseguem manter-se constantemente atualizados para atender as velozes exigências do mercado - que se refletem em todos os elos da cadeia produtiva dos complexos agroindustriais, principalmente no elo mais fraco: o pequeno produtor.

A partir de meados dos anos 1980 e principalmente durante os anos 1990, houve no Brasil uma série de alterações na política agrícola, no papel do Estado na economia e na relação do país com a economia internacional, que criaram um ambiente mais acirrado de concorrência no mercado agrícola, cuja implicação fundamental foi o crescimento de uma pressão sobre os agricultores para se ajustarem ao novo ambiente. Como reflexo desse processo, houve um forte aumento na produtividade física dos estabelecimentos familiares, superior à da patronal, mesmo com uma redução média da área cultivada (Homem de Melo, 2001).

Essa relação inversa entre aumento de rendimentos físicos dos estabelecimentos e redução de área agrícola utilizada reflete duas possibilidades conjuntas: um emprego mais intensivo de tecnologias modernas (insumos químicos, máquinas, fertilizantes etc.) e/ou a redução do número de agricultores familiares na atividade agrícola. Helfand e Rezende (2001) afirmam que os ganhos na produtividade da terra não implicam necessariamente a ocorrência de mudança tecnológica. Num contexto (década de 1990) de contração de área que afetou muitos produtos, rendimentos físicos maiores devem estar associados a aumentos em eficiência ao nível do setor, na medida em que terras de menor qualidade e produtores menos eficientes deixarem o setor. Essa é a questão que nos ocupa neste trabalho, relacionada às evidências empíricas de não crescimento da pluriatividade no Sul do Brasil; quer dizer, a vigência de uma agricultura moderna, orientada cada vez mais por critérios de mercado, cuja implicação econômica e social traduz-se em sistemática seleção de uma base cada vez mais estreita de agricultores hábeis 
em (e com recursos para) se ajustar às exigências da concorrência, em detrimento de parcelas bem maiores de produtores ineficientes.

No Sul do Brasil, onde predomina essa agricultura moderna - com largo acesso a tecnologias e à assistência técnica, observado em todos os estratos (de renda total e de tamanho) dos estabelecimentos (Tabelas 1, 2 e 3) -, a própria dinâmica dessa agricultura ocasiona a redução do número de produtores ${ }^{10}$.

Note-se, nas Tabelas 1 e 2, que a agricultura familiar da região Sul é, entre todas as regiões do país, a que mais tem acesso à tecnologia e à assistência técnica, muito acima da média nacional em todos os casos apresentados. Mais importante ainda é perceber que na região Sul é elevado o acesso à tecnologia e à assistência técnica por todos os tipos de agricultores familiares, dos de maior aos de menor renda total (RT). A Tabela 3 reforça essas informações, mostrando que os estabelecimentos agrícolas (em todas as faixas de tamanho de área) da região Sul são os que apresentam a maior proporção, comparativamente a todas as demais regiões, de número de tratores em relação ao número de estabelecimentos por classe de área.

Tabela 1: Agricultores familiares — acesso à tecnologia e à assistência técnica (em \%).

\begin{tabular}{|c|c|c|c|c|c|c|c|}
\hline \multirow[b]{2}{*}{ REGIÃO } & \multirow[b]{2}{*}{$\begin{array}{c}\text { Utiliza } \\
\text { assistência } \\
\text { Técnica }\end{array}$} & \multirow[b]{2}{*}{$\begin{array}{c}\text { Usa energia } \\
\text { Elétrica }\end{array}$} & \multicolumn{3}{|c|}{ Uso de força nos trabalhos } & \multirow[b]{2}{*}{$\begin{array}{l}\text { Usa adubos } \\
\text { e corretivos }\end{array}$} & \multirow[b]{2}{*}{$\begin{array}{c}\text { Faz } \\
\text { conservação } \\
\text { do solo }\end{array}$} \\
\hline & & & Só animal & $\begin{array}{l}\text { Só mecânica } \\
\text { ou mecânica } \\
\text { + animal }\end{array}$ & Manual & & \\
\hline Nordeste & 2,7 & 18,7 & 20,6 & 18,2 & 61,1 & 16,8 & 6,3 \\
\hline Centro-Oeste & 24,9 & 45,3 & 12,8 & 39,8 & 47,3 & 34,2 & 13,1 \\
\hline Norte & 5,7 & 9,3 & 9,3 & 3,7 & 87,1 & 9 & 0,7 \\
\hline Sudeste & 22,7 & 56,2 & 19 & 38,7 & 42,2 & 60,6 & 24,3 \\
\hline Sul & 47,2 & 73,5 & 37,2 & 48,4 & 14,3 & 77,1 & 44,9 \\
\hline BRASIL & 16,7 & 36,6 & 22,7 & 27,5 & 49,8 & 36,7 & 17,3 \\
\hline
\end{tabular}

Fonte: IBGE - Censo Agropecuário 1995/1996, in: MDA/FAO/INCRA (2000: 31).

Tabela 2: Agricultores familiares, segundo tipos — tecnologia e assistência técnica (em \%).

\begin{tabular}{|c|c|c|c|c|c|c|}
\hline \multirow[b]{2}{*}{ REGIĀO } & \multirow[b]{2}{*}{ Tipo } & \multirow{2}{*}{$\begin{array}{l}\text { Utiliza } \\
\text { assistência } \\
\text { técnica }\end{array}$} & \multirow[b]{2}{*}{$\begin{array}{c}\text { Usa energia } \\
\text { elétrica }\end{array}$} & \multicolumn{2}{|c|}{ Uso de força nos trabalhos } & \multirow[b]{2}{*}{$\begin{array}{c}\text { Usa adubos e } \\
\text { corretivos }\end{array}$} \\
\hline & & & & Só animal & $\begin{array}{c}\text { Só mecânica ou } \\
\text { mecânica + } \\
\text { animal }\end{array}$ & \\
\hline \multirow{4}{*}{ Sul } & $A$ & 74,7 & 88,9 & 25,2 & 70,7 & 94 \\
\hline & B & 54,3 & 81,8 & 42,4 & 50,9 & 86,6 \\
\hline & C & 34,6 & 68,1 & 45,8 & 39,9 & 71,9 \\
\hline & D & 27,6 & 55,7 & 32,9 & 35,9 & 56,9 \\
\hline \multirow{4}{*}{ Brasil } & A & 44 & 66,1 & 21,2 & 52,1 & 69,2 \\
\hline & $B$ & 25,1 & 48 & 28,1 & 32,4 & 50,6 \\
\hline & C & 11,9 & 31,9 & 25,5 & 22,2 & 32,7 \\
\hline & D & 8,6 & 26,5 & 18,9 & 22 & 24,4 \\
\hline
\end{tabular}

Legenda: Tipos A (Renda Total superior a três vezes o valor do VCO), B (RT superior, de uma vez até três vezes, o valor do VCO), C (RT superior, de metade até uma vez, o valor do VCO), D (RT igual ou inferior à metade do valor do VCO) - VCO: Valor do Custo de Oportunidade (valor da diária média estadual, acrescido de $20 \%$ e multiplicado pelo número de dias úteis do ano - calculado em 260).

Fonte: IBGE - Censo Agropecuário 1995/1996, in: MDA/FAO/INCRA (2000: 54).

${ }^{10}$ Conforme pode se depreender de trabalhos como os de Alves e Homem de Souza (2000), Goularti Filho (2001), E. Alves (2001), Homem de Melo (2001). 
Tabela 3: Distribuição do número de tratores em relação ao número de estabelecimentos (familiares e patronais) por classe de área e regiões (em \%).

\begin{tabular}{l|c|c|c|c|c}
\hline \multicolumn{1}{c|}{$\begin{array}{c}\text { CLASSES } \\
\text { (Área em hectares) }\end{array}$} & Norte & Nordeste & Centro-Oeste & Sudeste & Sul \\
\hline$<10$ & 0,21 & 0,32 & 3,87 & 7,11 & 13,34 \\
{$[10,20]$} & 0,39 & 1,08 & 6,48 & 14,38 & 19,09 \\
{$[20,50]$} & 0,89 & 1,87 & 8,78 & 20,37 & 36,44 \\
{$[50,100]$} & 1,48 & 3,73 & 14,31 & 28,16 & 49,02 \\
{$[100,200]$} & 2,67 & 7,69 & 24,82 & 37,86 & 53,29 \\
{$[200,500]$} & 9,45 & 15,4 & 47,24 & 51,01 & 62,1 \\
{$[500,1.000]$} & 22,78 & 27,34 & 65,68 & 63,06 & 70,64 \\
{$[1.000,10.000]$} & 44,5 & 42,24 & 80,35 & 71,68 & 77,09 \\
$>10.000$ & 67,06 & 75,77 & 88,66 & 70,11 & 66,67 \\
\hline Região & 2,6 & 1,59 & 19,66 & 25,62 \\
\hline Fonte: IBGE - Censo Agropecuário $1995 / 1996$, in: E. Alves, et al. (1999).
\end{tabular}

O crescimento da produtividade (inovações tecnológicas) faz-se acompanhar da redução do número de produtores. Alves e Homem de Souza (2000) abordam esse aspecto no caso da produção brasileira de leite, caracteristicamente de pequenos produtores. Segundo esses autores, “(...) os compradores de leite do mercado formal [agroindústrias], principalmente mediante preços mais baixos, estão se livrando da pequena produção, empurrando-a para o mercado informal” (Alves e Homem de Souza, 2000:21).

Assim sendo, no que concerne às perspectivas em relação ao futuro dos produtores de leite em um contexto de aumento da produtividade no setor, concluem os autores: "Mas, se todos ampliarem a escala de produção (...) recairá na diminuição do número de produtores. (...)] não se pode cuidar da modernização da produção de leite sem considerar seus efeitos no número de produtores" (Alves e Homem de Souza, 2000:22).

Um outro exemplo de declínio do número de produtores rurais é o apresentado por Goularti Filho (2001) em seu estudo sobre o processo de reestruturação patrimonial, ocorrido no complexo agroindustrial catarinense em favor de multinacionais. Segundo esse autor, o processo de desnacionalização ocorrido nos anos 90 no complexo agroindustrial catarinense foi acompanhado de redução brutal no número de suinocultores e de uma readaptação dos avicultores. De acordo com seus dados, em 1990 havia 36.050 produtores (suinocultores e avicultores) integrados às redes das empresas Sadia, Aurora, Perdigão e Chapecó. Em 1999, esse número encontrava-se reduzido a 22.198 , correspondendo a uma queda geral de $38,4 \%$ em uma década.

Em suma, essa rápida abordagem dos impactos da modernização agropecuária sobre o número de produtores agropecuários possui o único intuito de mostrar a contradição, intrínseca à lógica da modernização, que se expressa, simultaneamente, entre o aumento da produtividade no setor agropecuário de uma dada região (no caso, região Sul) - conduzido por uma base estreita de agricultores eficientes - e a redução do número de pequenos produtores familiares "inaptos". O resultado é a configuração de uma tendência à redução do número de famílias pluriativas, acompanhando o declínio do número de produtores do setor.

Isso não significa necessariamente que as famílias de produtores progressivamente alijados desse processo largarão a atividade agrícola, deixando de ser famílias de conta-próprias agrícolas ou pluriativas e convertendo-se em famílias 
de outros tipos. Ou seja, não significa que automaticamente os produtores familiares, por não se ajustarem ao novo regime concorrencial, largarão a atividade agrícola. Contudo, por ficarem marginalizados do processo de modernização (e de integração aos circuitos comerciais e produtivos dos agronegócios), haverá sempre a tendência a abandonarem a atividade agrícola, sobretudo tendo-se em vista alguns fatores que contribuem para essa decisão (forçada pelas circunstâncias). Quais sejam: a) a difusão, através dos meios de comunicação de massa, dos hábitos e necessidades urbanos; b) a crescente dificuldade de manter uma atividade agrícola não remuneradora; c) conjunturas duradouras de crise no setor agrícola; d) entornos rurais dinâmicos, proporcionando maiores oportunidades ocupacionais fora da agricultura; e) descaso histórico do Estado - materializado em políticas públicas específicas - no tocante ao amparo aos pequenos produtores "inviáveis", não os incentivando a permanecer com algum tipo de atividade agrícola - à semelhança, por exemplo, da PAC da União Européia (Nascimento, 2005a, 2005b).

A combinação de todos esses fatores justifica nossa hipótese de que a pluriatividade no Sul não encontra condições objetivas para crescer. Vamos, enfim, aos dados que podem ser extraídos das PNADs.

\section{Análise dos dados das PNADs dos anos 1990}

A Tabela 4 confirma as observações tecidas anteriormente. Nessa Tabela pode-se ver as taxas de crescimento de diferentes tipos de famílias sulinas residentes nas áreas rurais não metropolitanas agropecuárias. Note-se o generalizado declínio significativo do número de famílias conta-próprias pluriativas (e agrícolas) e, ao contrário, o crescimento significativo do número de famílias não agrícolas (conta-próprias e assalariados), em dois períodos da década de 1990. Observe-se que, embora a taxa de crescimento negativa da pluriatividade intersetorial não seja significativa, significa não crescimento em nenhum dos dois períodos.

Tabela 4: Evolução dos tipos de famílias segundo

o local de domicílio - Sul, 1992-99 e 1995-99.

\begin{tabular}{|c|c|c|c|c|c|}
\hline \multirow{2}{*}{$\begin{array}{l}\text { LOCAL DOMICÍLIO / } \\
\text { TIPO DE FAMÍLIA }\end{array}$} & \multirow[t]{2}{*}{$\begin{array}{c}1999 \\
\text { (mil fam.) }\end{array}$} & \multicolumn{2}{|c|}{$\begin{array}{r}\text { tx cresc. } \\
\text { (\% a.a.) } \\
\end{array}$} & \multicolumn{2}{|c|}{$\begin{array}{c}\text { tx cresc. } \\
\text { (\% a.a.) }\end{array}$} \\
\hline & & \multicolumn{2}{|c|}{$1992-99$ a } & \multicolumn{2}{|c|}{$1995-99$ a } \\
\hline \multicolumn{6}{|l|}{ RURAL AGROPECUÁRIO } \\
\hline Conta-Própria & 671 & $-2,0$ & $* * *$ & $-2,0$ & $* * *$ \\
\hline Agrícola & 467 & $-2,9$ & $* * *$ & $-2,6$ & $* * *$ \\
\hline Pluriativo & 138 & $-2,2$ & $* *$ & $-2,8$ & \\
\hline Tradicional (agrícola com agrícola) & 27 & $-4,0$ & $* * *$ & $-5,5$ & $* * *$ \\
\hline Intersetorial (agr. com não-agríc.) & 109 & $-1,8$ & & $-2,5$ & \\
\hline Não-agrícola & 67 & 9,4 & $* * *$ & 5,9 & \\
\hline Empregados & 428 & 3,2 & $* * *$ & 4,4 & $* * *$ \\
\hline Agrícola & 185 & 0,5 & & 1,3 & \\
\hline Pluriativo & 42 & $-1,0$ & & $-3,8$ & \\
\hline Não-agrícola & 201 & 7,6 & $* * *$ & 10,1 & $* * *$ \\
\hline
\end{tabular}

Nota: exclusive as famílias sem declaração de renda e tipos de familia com menos de 6 observações a) estimativa do coeficiente de uma regressão log-linear contra o tempo. Nesse caso, o teste t indica a existência ou não de uma tendência nos dados. ${ }^{* * *},{ }^{* *}$, * significam respectivamente $5 \%, 10 \%$ e $20 \%$. Fonte: PNAD/IBGE - Tabulações Especiais do Projeto Rúrbano - Elaboração própria. 
A Tabela 5 apresenta taxas de crescimento das famílias sulinas de conta-próprias agrícolas e pluriativas (agricultura familiar) com algum membro com algum tipo de acesso à terra, segundo faixas de tamanho de área dos estabelecimentos nos períodos 1992-1999 e 1995--1999. Não se nota um único caso de crescimento da pluriatividade, em nenhum dos dois períodos analisados. Há dois registros de queda significativa (sentido estatístico) da pluriatividade sulina total, "puxada" tanto pela pluriatividade tradicional como pela pluriatividade intersetorial.

A Tabela 5 mostra ainda - como questão importante para a discussão do trabalho - que, na região Sul, a agricultura familiar (o total de famílias contapróprias agrícolas e pluriativas), em quase todos os estratos de tamanho de estabelecimentos, reduz-se sistemática e significativamente em ambos os períodos analisados. Na maioria desses casos, a pluriatividade sulina não contribuiu para evitar essa queda. Pelo contrário, em alguns casos, a pluriatividade sulina intersetorial e tradicional apresentou também taxas de crescimento negativas e significativas (sentido estatístico).

Tabela 5: Evolução dos tipos de famílias de conta-próprias segundo o local de domicílio e faixa de área - Sul, 1992-1999 e 1995-1999.

\begin{tabular}{|c|c|c|c|c|c|c|c|c|c|}
\hline \multirow{3}{*}{$\begin{array}{l}\text { LOCAL DOMICÍLIO / } \\
\text { TIPO DE FAMÍLIA }\end{array}$} & \multicolumn{2}{|c|}{$\begin{array}{l}\text { menos } \\
\text { de 20ha }\end{array}$} & \multicolumn{2}{|c|}{$\begin{array}{c}\text { de } 20 \text { ha a menos de } \\
100 \text { ha }\end{array}$} & \multicolumn{2}{|c|}{ de 100 ha e mais } & \multirow{2}{*}{$\begin{array}{l}\begin{array}{c}\text { menos } \\
\text { de } 20 \text { ha }\end{array} \\
\text { tx. cresc. } \\
\text { ( } \% \text { a.a.) }\end{array}$} & \multirow{2}{*}{$\begin{array}{c}\text { de } 20 \text { ha a } \\
\text { menos de } \\
100 \text { ha } \\
\text { tx. cresc. } \\
(\% \text { a.a.) }\end{array}$} & \multirow{2}{*}{$\begin{array}{c}\text { de } 100 \text { ha e } \\
\text { mais }\end{array}$} \\
\hline & \multirow{2}{*}{$\begin{array}{r}1999 \\
\text { (mil } \\
\text { fam.) }\end{array}$} & $\begin{array}{r}\text { tx. cresc. } \\
\text { (\% a.a.) }\end{array}$ & \multirow{2}{*}{$\begin{array}{r}1999 \\
\text { (mil } \\
\text { fam.) } \\
\end{array}$} & \multirow{2}{*}{$\begin{array}{l}\text { tx.cresc. } \\
\text { (\% a.a.) } \\
1992 / 99^{a}\end{array}$} & \multirow{2}{*}{$\begin{array}{r}1999 \\
\text { (mil } \\
\text { fam.) }\end{array}$} & $\begin{array}{l}\text { tx. cresc. } \\
\text { (\% a.a.) }\end{array}$ & & & \\
\hline & & $1992 / 99$ a & & & & $1992 / 99^{a}$ & $1995 / 99^{a}$ & $1995 / 99$ a & 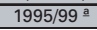 \\
\hline \multicolumn{10}{|l|}{$\begin{array}{l}\text { NÄO METROPOLITANO } \\
\text { RURAL AGROPECUÁRIO }\end{array}$} \\
\hline Conta-próprias (agrícolas mais pluriativos) & 142 & $-7,1 * * *$ & 355 & $-1,7^{* * *}$ & 82 & $2,9 * *$ & $-6,3 * *$ & $-2,5^{* *}$ & $5,3 *$ \\
\hline Agrícola & 97 & $-8,0 * * *$ & 288 & $-2,2 * * *$ & 70 & $5,3 * * *$ & $-6,8 * * *$ & $-3,0 * *$ & $7,6^{* *}$ \\
\hline Pluriativo & 45 & $-4,7^{* * *}$ & 68 & 1,4 & 13 & $-9,4 * * *$ & $-5,1$ & $-0,1$ & $-8,3$ \\
\hline Tradicional (agrícola com agrícola) & 9 & $-8,7 * * *$ & 12 & $-2,8$ & 4 & - & $-5,3$ & $-7,8$ & $\cdots$ \\
\hline Intersetorial (agr. com não-agríc.) & 36 & $-3,4^{*}$ & 56 & 1,4 & 9 & $-9,4 * * *$ & $-4,8$ & $-0,1$ & $-8,3$ \\
\hline
\end{tabular}

Nota: exclusive as famílias sem declaração de renda e tipos de familia com menos de 6 observaçōes na amostra Os "- -" indicam que o tamanho da amostra nāo é significativo (menos de 6 casos).

a) estimativa do coeficiente de uma regressāo log-linear contra o tempo. Nesse caso, o teste t indica a existência ou não de uma tendência nos dados. ${ }^{* *},{ }^{* *}$, ${ }^{*}$ significam respectivamente $5 \%, 10 \%$ e $20 \%$

Fonte: PNAD/IBGE - Tabulações Especiais do Projeto Rurbano - Elaboração própria.

Diante desses dados, é difícil aceitar o argumento de que uma das explicações para a queda da pluriatividade nas áreas rurais do estado do Rio Grande do Sul seja a perda de plantas industriais dos setores de “(...) calçados e confecção, os quais optaram por suspender parcial ou totalmente o funcionamento de unidades de produção instaladas na zona rural dos municípios e/ou em pequenas localidades" (Sacco dos Anjos, 2003:305). Schneider e Navarro também procuram explicar a diminuição do contingente de famílias pluriativas nas áreas rurais do estado do Rio Grande do Sul, nos anos 90, atribuindo-a ao “(...) estancamento das atividades da indústria calçadista no estado, grandemente promotora desse tipo de ocupação e combinação com domicílio rural".

Em primeiro lugar, a dificuldade de aceitar referidos argumentos reside na constatação de que, embora tenham ocorrido transformações produtivas nas indústrias calçadistas e de vestuário da região Sul, com deslocamento de plantas industriais para outras regiões, não houve perdas no emprego nesses setores da 
região Sul. A Tabela 6 apresenta a evolução da população (residente nas áreas rurais agropecuárias dos estados do $\mathrm{PR}, \mathrm{SC}$ e RS) ocupada em diferentes setores de atividade não agrícola nos anos 90 . Note-se que na região Sul como um todo houve forte crescimento significativo da ocupação na "indústria do vestuário" (nos três períodos referenciados) e na "indústria de calçados" (14,2\%a.a., em 1995-1999); no RS houve crescimento significativo da ocupação na "indústria de calçados" na ordem de 15,5\%a.a. (1995-1999); em SC, as taxas de crescimento do número de pessoas ocupadas na "indústria do vestuário" foram significativas nos três períodos apresentados. Note-se também que, em geral, cresceu significativamente a PEA rural não agrícola total.

Tabela 6: Evolução da população ocupada segundo local dos domicílios e ramos de atividades. PEA restrita. Sul, 1992-1999.

\begin{tabular}{|c|c|c|c|c|c|}
\hline $\begin{array}{l}\text { ÁREA CENSITÁRIA / } \\
\text { SETOR PRINCIPAL }\end{array}$ & $\begin{array}{c}1992 \\
(1.000)\end{array}$ & $\begin{array}{c}1999 \\
(1.000)\end{array}$ & $\begin{array}{c}1992-97 \text { b } \\
\text { (\%a.a.) }\end{array}$ & $\begin{array}{c}1992-99 \text { b } \\
\text { (\%a.a.) }\end{array}$ & $\begin{array}{c}1995-99 \text { b } \\
\text { (\%a.a.) }\end{array}$ \\
\hline \multicolumn{6}{|l|}{$\begin{array}{l}\text { NĀO METROPOLITANO } \\
\text { RURAL AGROPECUÁRIO }\end{array}$} \\
\hline \multicolumn{6}{|c|}{ SUL } \\
\hline $\begin{array}{l}\text { Não-agrícola (total) } \\
\text { indústria de calçados } \\
\text { industria vestuário }\end{array}$ & $\begin{array}{c}523 \\
27 \\
6\end{array}$ & $\begin{array}{c}685 \\
35 \\
21\end{array}$ & $\begin{array}{r}4,3 * * * \\
-3,9 \\
16,7 * * *\end{array}$ & $\begin{array}{r}3,9 * * * \\
1,8 \\
17,8 * * *\end{array}$ & $\begin{array}{r}5,1 * * * \\
14,2 * * * \\
27,4 * * *\end{array}$ \\
\hline \multicolumn{6}{|c|}{ Rio Grande do Sul } \\
\hline $\begin{array}{l}\text { Não-agrícola (total) } \\
\text { indústria de calçados }\end{array}$ & $\begin{array}{c}258 \\
26\end{array}$ & $\begin{array}{c}300 \\
34\end{array}$ & $\begin{array}{r}1,8 \\
-4,1\end{array}$ & $\begin{array}{l}2,22^{* * *} \\
2,0\end{array}$ & $\begin{array}{r}4,5 * * * \\
15,5 * * *\end{array}$ \\
\hline \multicolumn{6}{|c|}{ Paraná } \\
\hline Não-agrícola (total) & 116 & 167 & $3,4 *$ & $5,5 * * *$ & $9,8 * * *$ \\
\hline \multicolumn{6}{|c|}{ Santa Catarina } \\
\hline $\begin{array}{l}\text { Não-agrícola (total) } \\
\text { industia vestuário }\end{array}$ & $\begin{array}{c}149 \\
4\end{array}$ & $\begin{array}{c}218 \\
16\end{array}$ & $\begin{array}{l}8,9 * * \\
9,9 *\end{array}$ & $\begin{array}{r}5,1 * * * \\
18,9 * * *\end{array}$ & $\begin{array}{r}2,4 \\
27,3 * *\end{array}$ \\
\hline \multicolumn{6}{|c|}{$\begin{array}{l}\text { a) exclui pessoas com menos de } 15 \text { h de ocupação e exclusivamente dedicadas à autoconstrução e à } \\
\text { produção para o autoconsumo. } \\
\text { b) estimativa do coeficiente de uma regressão log-linear contra o tempo. Nesse caso, o teste t indica a existência } \\
\text { ou não de uma tendência nos dados. }{ }^{* * *} \text {. }^{* *} \text {, }^{*} \text { significam respectivamente } 5 \%, 10 \% \text { e } 20 \% \text {. } \\
\text { c) exclusive as famílias sem declaração de renda e tipos de familia com menos de } 6 \text { observações na amostra. } \\
\text { Fonte: PNAD/IBGE - Tabulações Especiais do Projeto Rurbano - Elaboração própria. }\end{array}$} \\
\hline
\end{tabular}

Em segundo lugar, outro dado que dificulta aceitar referidos argumentos concerne ao acelerado crescimento das famílias não agrícolas (conta-próprias e assalariados) no rural agropecuário de toda a região Sul (Tabela 4) e do Rio Grande do Sul (Tabela 6a), uma vez que o suposto efeito negativo da redução das atividades dos setores calçadista e têxtil sobre as famílias pluriativas deveria ter-se refletido também sobre as famílias rurais não agrícolas do Sul e do RS; porém, não é, em absoluto, o que os dados revelam. 
Tabela 6a: Evolução dos tipos de famílias segundo o local de domicílio:

Rio Grande do Sul, 1992/99 e 1995/99.

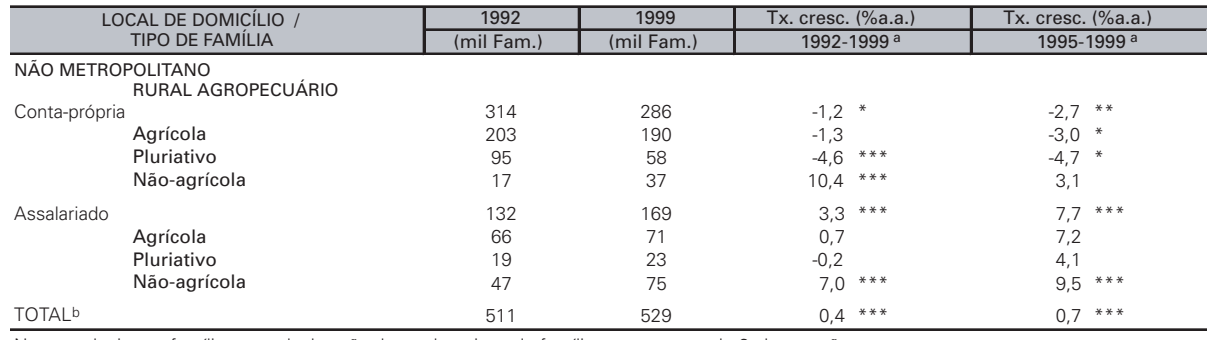

Nota: exclusive as famílias sem declaracão de renda e tipos de famílias com menos de 6 observacões na amostra

a) Estimativa do coeficiente de uma regressão log-linear contra o tempo. Neste caso, o teste t indica a existência ou não de uma

tendência nos dados. ${ }^{* *},{ }^{* *},{ }^{*}$ significam respectivamente $5 \%, 10 \%$ e $20 \%$.

b) Total de famílias (empregadoras, conta-próprias, assalariados, não ocupados).

Fonte: PNAD/IBGE - Tabulações Especiais do Projeto Rurbano, IE/UFU.

Por fim, a evidência do declínio (ou do não crescimento) da pluriatividade na região Sul deve ser tratada como resultante de um elemento estrutural e não decorrente simplesmente de fatores conjunturais. A queda da pluriatividade no Sul decorre de um elemento estrutural objetivado no próprio modelo agrícola difundido na região, como já vínhamos defendendo. Sacco dos Anjos (2003) atribui, com muita propriedade, a queda da pluriatividade no Rio Grande do Sul, como sua segunda explicação à profunda reestruturação sofrida pelo conjunto da agricultura familiar nos anos 1990. No presente trabalho, entretanto, queremos reforçar ainda a idéia de que a "crise" "11 agrícola (que levou à reestruturação do setor) nos anos 1990 deve ser tratada como decorrente, uma manifestação daquele elemento estrutural. E que, portanto, esse é "o" elemento que, na ausência de políticas compensatórias, impede a pluriatividade de crescer, levando-a até mesmo ao declínio - caso da região Sul. Significa dizer que, havendo ou não crise no setor, a lógica interna da modernização agrícola (elemento estrutural) permanece disciplinando o setor e ameaçando (de expulsão) os produtores ineficientes havendo, entre eles, muitos pequenos produtores familiares pluriativos. Por essa razão, julgamos imprescindível uma ação pública abrangente, no sentido de compensar os segmentos de pequenos produtores familiares dos efeitos negativos desse processo, caso a sociedade decida promover o crescimento da pluriatividade no Sul do país. Sem essa ação, a pluriatividade não acompanhará o ritmo de crescimento dos problemas a enfrentar.

Em regiões que sofrem processos de crescimento econômico e modernização de suas estruturas produtivas, para que a pluriatividade possa crescer ela deve ser, primeiramente, compreendida e aceita socialmente como instrumento importante para o futuro do mundo rural para, então, ser pensada, planejada e provocada. Não dá para esperar que ela cresça automaticamente pela influência dos

${ }^{11}$ Crise entre aspas porque não se pode generalizar para todo o conjunto dos produtores agrícolas (Nascimento, 2005b). 
mecanismos de mercado; muito menos por pura iniciativa interna às unidades familiares.

$\mathrm{Na}$ UE o crescimento da pluriatividade decorre não da cultura campesina do seu passado, mas, sobretudo, de um conjunto de políticas de organização do setor agrícola por parte do Estado, através da PAC. Esta incentivou a busca obsessiva por elevação da produtividade e, em razão do seu sucesso, as unidades produtivas puderam liberar parte da força de trabalho familiar para se ocupar em outros setores. Essa é parte da explicação do "fenômeno" da pluriatividade na UE. A outra parte decorre da idéia de que a pluriatividade é uma construção política. Nos primeiros anos da PAC (pré-reforma) a pluriatividade foi viabilizada não somente pelos elevados níveis de produtividade, mas também porque, no ímpeto de atender a amplos interesses (setores e países), a PAC favoreceu os produtores mais eficientes e produtivos sem, contudo, penalizar, pela exposição às leis do mercado, os menos eficientes, garantindo a esses últimos a realização da sua produção com preços elevados; não permitindo, desse modo, que houvesse uma ampla exclusão ou ajuste estrutural das unidades produtivas (Nascimento, 2005a).

Não é esse o caso do Sul do Brasil. Por essa razão, enquanto acusa-se ampliação da pluriatividade no meio rural da UE, ${ }^{12}$ no Sul do Brasil os dados denunciam tendência contrária.

Ocorre que na UE a sociedade entendeu que, sem apoio público, as tendências de desemprego estrutural na indústria e na agricultura, sem completa compensação pelo lado do setor de serviços, evidenciam a inexorável inocuidade da pluriatividade frente às dimensões dos desafios quanto à ocupação e geração de renda da população rural. Não é sem razão que a reforma da PAC (1992) implementou ajudas diretas para assegurar o sustento da agricultura familiar (do "novo agricultor" ${ }^{13}$ ), das "atividades agrícolas" (não necessariamente voltadas para os mercados de produtos), e, com isso, possibilita-se mais crescimento da pluriatividade. $^{14}$

A pluriatividade não é, portanto, algo que espontaneamente ou "naturalmente" prospera, isenta de concepções políticas, de conflitos de classe, de projetos norteadores da construção de algum tipo de sociedade e de nação. É pelos motivos brevemente descritos acima, e por tantos outros apoios governamentais, que a pluriatividade progride na UE. No Sul do Brasil, como não existe tal apoio, a pluriatividade não cresce nem está cumprindo a contento o papel de ser o sustentáculo da agricultura familiar, evitando o aprofundamento do processo de proletarização dos pequenos produtores familiares.

\footnotetext{
${ }^{12}$ Arkleton Trust (1992).

${ }^{13}$ Muitos dos agricultores, antes beneficiados pela PAC, para continuar a sê-lo terão de aceitar a nova identificação com os “jardineiros da natureza” (Nascimento, 2005a).

${ }^{14}$ Ver maiores detalhes em Nascimento (2005a).
} 
A partir de janeiro de 1999 houve uma inflexão no regime de taxa de câmbio vigente desde a implementação do Plano Real. O sistema que há mais de quatro anos operava com o câmbio fixo e sobrevalorizado, passou a funcionar com uma taxa de câmbio flutuante e desvalorizada. O novo regime cambial passou a funcionar, por um lado, como uma proteção para os produtores agrícolas nacionais contra a concorrência dos produtos importados; por outro lado, favoreceu a produção interna comercializável no mercado internacional. A agricultura, portanto, deixou de ter na taxa de câmbio uma variável negativa para seu desempenho, respondendo positivamente à mudança no regime cambial (Gasques e Spolador, 2003; Brandão et al., 2005).

Do lado dos produtores menores e mais incapacitados a responder positivamente à concorrência, pode-se supor também que o novo regime cambial trouxe uma redução da pressão da concorrência externa, o que rebate na diminuição da pressão, intrínseca à dinâmica da concorrência intercapitalista, por aumentos de eficiência e ajuste alocativo de fatores. Essas observações são importantes na medida em que podem explicar o comportamento quantitativo das famílias rurais sulinas para o período de 2001 a 2004.

A Tabela 7 mostra uma quase generalizada estabilidade (estatística) no tocante à evolução quantitativa das famílias - segundo o ramo de atividade em que estão ocupadas (agrícola, pluriativa, não agrícola) — residentes nas áreas rurais agropecuárias da região Sul, no quadriênio 2001-2004. Talvez, parte das famílias que deixaram de ser conta-próprias agrícolas (redução significativa de $2,1 \%$ a.a.), tornaram-se ou famílias pluriativas tradicionais ou famílias de assalariados agrícolas.

Note-se ainda na Tabela 7 que o número de famílias pluriativas, no agregado da agricultura familiar sulina (conta-própria agrícola mais pluriativo), permaneceu estabilizado (sentido estatístico). A despeito disso, ao desagregar a pluriatividade das famílias de conta-próprias entre pluriatividade tradicional e pluriatividade intersetorial, pode-se notar o crescimento significativo $(16,1 \%)$ unicamente das famílias de conta-próprias da pluriatividade tradicional. Esses dados reafirmam a evidência de que o crescimento da pluriatividade (associada às atividades não agrícolas) na região Sul apresenta-se comprometido. 
Tabela 7: Evolução do número de famílias, segundo o tipo e local de domicílio - Sul, 2001-2004

\begin{tabular}{|c|c|c|c|c|c|}
\hline \multirow{2}{*}{$\begin{array}{l}\text { LOCAL DOMICÍLIO / } \\
\text { TIPO DE FAMÍLIA }\end{array}$} & \multirow{2}{*}{$\begin{array}{c}2001 \\
\text { (mil fam.) }\end{array}$} & \multirow{2}{*}{$\begin{array}{c}2002 \\
\text { (mil fam.) }\end{array}$} & \multirow{2}{*}{$\begin{array}{c}2003 \\
\text { (mil fam.) }\end{array}$} & \multirow{2}{*}{$\begin{array}{c}2004 \\
\text { (mil fam.) }\end{array}$} & \multirow{2}{*}{$\frac{\text { tx. cresc. (\% a.a.) }}{2001-2004 \text { a }}$} \\
\hline & & & & & \\
\hline \multicolumn{6}{|l|}{ NÄO METROPOLITANO } \\
\hline \multicolumn{6}{|l|}{ RURAL AGROPECUÁRIO } \\
\hline Conta-própria & 697 & 723 & 715 & 708 & 0,3 \\
\hline Agrícola & 501 & 504 & 492 & 472 & $-2,1 *$ \\
\hline Pluriativo & 142 & 173 & 152 & 178 & 5,5 \\
\hline Tradicional (agrícola com agrícola) & 24 & 38 & 33 & 41 & $16,1 *$ \\
\hline Intersetorial (agríc. com não agríc.) & 118 & 135 & 119 & 136 & 3,1 \\
\hline Não-agrícola & 54 & 46 & 71 & 59 & 7,1 \\
\hline \multicolumn{6}{|c|}{$--\overline{A g r i c u l t u r a ~ f a m i l i a r ~(c o n t a-p r o ́ p r i a s ~ a g r i ́ c o l a ~ e ~ p l u r i a t i v o) ~}$} \\
\hline $\begin{array}{l}\text { Agricultura familiar (conta-proprias agricola e plurıatıvo) } \\
\text { Agrícola }\end{array}$ & $\begin{array}{l}643 \\
501\end{array}$ & $\begin{array}{l}677 \\
504\end{array}$ & $\begin{array}{l}644 \\
492\end{array}$ & $\begin{array}{l}649 \\
472\end{array}$ & $\begin{array}{l}-0,2 \\
-2,1 *\end{array}$ \\
\hline Pluriativo & 142 & 173 & 152 & 178 & 5,5 \\
\hline Tradicional (agrícola com agrícola) & 24 & 38 & 33 & 41 & $16,1 *$ \\
\hline Intersetorial (agríc. com não agríc.) & 118 & 135 & 119 & 136 & 3,1 \\
\hline - - - - Assalariados - - - - - - - - - - - - - & $--\overline{320}$ & $-\overline{3} 3 \overline{4}$ & $--\overline{3} 0^{-}$ & $---\overline{34} \overline{3}$ & $---\overline{9} *---$ \\
\hline Agrícola & 148 & 144 & 159 & 164 & $4,1 *$ \\
\hline Pluriativo & 40 & 51 & 47 & 42 & 0,8 \\
\hline Não-agrícola & 132 & 139 & 124 & 136 & $-0,2$ \\
\hline
\end{tabular}

Nota: exclusive as famílias sem declaração de renda e tipos de familia com menos de 6 observações.

a) estimativa do coeficiente de uma regressão log-linear contra o tempo. Nesse caso, o teste t indica a existência ou não de uma tendência nos dados.

****** $*$ significam respectivamente $5 \%, 10 \%$ e $20 \%$

Fonte: PNAD/IBGE - Tabulações Especiais do Projeto Rurbano - Elaboração própria.

A Tabela 8 mostra as taxas de crescimento do número de produtores familiares sulinos (agrícolas e pluriativos) com algum acesso à terra, segundo faixas de tamanho de estabelecimento. Essa Tabela confirma as observações da Tabela anterior; ou seja, que a pluriatividade intersetorial no seio da agricultura familiar sulina permanece sem crescer (sentido estatístico), e que somente a pluriatividade tradicional apresentou taxas significativas de crescimento, embora somente no estrato entre 20 e 100 hectares.

Tabela 8: Evolução da agricultura familiar, segundo tipos de famílias, local de domicílio e faixas de área - Sul, 2001-2004.

\begin{tabular}{|c|c|c|c|c|c|c|}
\hline \multirow{3}{*}{$\begin{array}{l}\text { LOCAL DOMICÍLIO / } \\
\text { TIPO DE FAMILIA }\end{array}$} & \multicolumn{2}{|c|}{ menos de 20 ha } & \multicolumn{2}{|c|}{$\begin{array}{l}\text { de } 20 \text { a menos } \\
\text { de } 100 \text { ha }\end{array}$} & \multicolumn{2}{|c|}{ de 100 ha e mais } \\
\hline & \multirow{2}{*}{$\begin{array}{r}2004 \\
\text { (mil } \\
\text { fam.) }\end{array}$} & $\begin{array}{l}\text { tx. cresc. } \\
(\% \text { a.a. })\end{array}$ & \multirow{2}{*}{$\begin{array}{r}2004 \\
\text { (Mil } \\
\text { Fam.) }\end{array}$} & $\begin{array}{l}\text { tx. cresc. } \\
(\% \text { a.a. })\end{array}$ & \multirow{2}{*}{$\begin{array}{r}2004 \\
\text { (Mil } \\
\text { Fam.) }\end{array}$} & $\begin{array}{r}\text { tx. cresc. } \\
(\% \text { a.a. })\end{array}$ \\
\hline & & $2001-2004$ a & & $2001-2004^{\text {a }}$ & & $2001-2004^{\text {a }}$ \\
\hline \multicolumn{7}{|l|}{ NẢO METROPOLITANO } \\
\hline \multicolumn{7}{|l|}{ RURAL AGROPECUÁRIO } \\
\hline Agricultura familiar & 405 & 0,1 & 181 & $-1,6$ & 25 & 4,9 \\
\hline Agrícola & 296 & $-2,1$ & 138 & $-3,7$ & 22 & 9,0 \\
\hline Pluriativo & 109 & 7,5 & 43 & $7,0 *$ & 4 & $-10,0$ \\
\hline Tradicional (agrícola + agrícola) & 28 & 14,6 & 11 & $23,8 * * *$ & 1 & - \\
\hline Intersetorial (agríc. + não agrícola) & 81 & 5,5 & 32 & 2,9 & 3 & $-3,6$ \\
\hline
\end{tabular}

Nota: exclusive as famílias sem declaração de renda e tipos de familia com menos de 6 observações

a) estimativa do coeficiente de uma regressão log-linear contra o tempo. Neste caso, o teste t indica a existência ou não de uma tendência nos dados.***, ** * significam respectivamente $5 \%, 10 \%$ e $20 \%$.

Fonte: PNAD/IBGE - Tabulaçōes Especiais do Projeto Rurbano - Elaboração própria.

Uma razão para o crescimento da pluriatividade tradicional sulina, no período 2001-2004, pode ser encontrada na Tabela 9, que mostra o crescimento significativo da PEA agrícola assalariada. Ou seja, famílias de conta-próprias agrícolas podem ter se tornado famílias conta-próprias pluriativas tradicionais em decorrência do assalariamento (em outro estabelecimento agrícola) de algum de seus membros. Note-se ainda que a PEA não agrícola assalariada cresceu significativamente e que, a despeito disso, o contingente das famílias pluriativas intersetoriais não cresceu (sentido estatístico), conforme apontado anteriormente. 
Tabela 9: População ocupada e desocupada, segundo ramo de atividade, posição na ocupação e local de domicílio: Sul - 2001-2004. (PEA restrita*)

\begin{tabular}{|c|c|c|c|c|c|}
\hline \multirow{2}{*}{$\begin{array}{l}\text { LOCAL DOMICÍLIO / } \\
\text { TIPO DE FAMÍLIA }\end{array}$} & \multirow{2}{*}{$\begin{array}{l}2001 \\
\text { (mil pessoas) }\end{array}$} & \multirow{2}{*}{$\begin{array}{c}2002 \\
\text { (mil pessoas) }\end{array}$} & \multirow{2}{*}{$\begin{array}{c}2003 \\
\text { (mil pessoas) }\end{array}$} & \multirow{2}{*}{$\begin{array}{l}2004 \\
\text { (mil pessoas) }\end{array}$} & tx. cresc. $(\%$ a.a.) \\
\hline & & & & & $2001-2004^{a}$ \\
\hline \multicolumn{6}{|l|}{$\begin{array}{l}\text { NÄO METROPOLITANO } \\
\text { Rural Agropecuário }\end{array}$} \\
\hline $\begin{array}{l}\text { Agrícola } \\
\text { Assalariado } \\
\text { Conta-própria } \\
\text { Empregador } \\
\text { Não remunerado }\end{array}$ & $\begin{array}{c}1812 \\
270 \\
696 \\
51 \\
795\end{array}$ & $\begin{array}{c}1860 \\
268 \\
725 \\
35 \\
832\end{array}$ & $\begin{array}{c}1831 \\
300 \\
712 \\
47 \\
772\end{array}$ & $\begin{array}{c}1830 \\
305 \\
701 \\
56 \\
768\end{array}$ & $\begin{array}{r}0,1 \\
4,9 * * \\
0,0 \\
5,8 \\
-1,8\end{array}$ \\
\hline $\begin{array}{l}\text { Näo agrícola } \\
\text { Assalariado } \\
\text { Conta-própria } \\
\text { Empregador } \\
\text { Não remunerado }\end{array}$ & $\begin{array}{c}516 \\
377 \\
102 \\
20 \\
17\end{array}$ & $\begin{array}{c}543 \\
420 \\
88 \\
22 \\
14\end{array}$ & $\begin{array}{c}557 \\
409 \\
120 \\
17 \\
11\end{array}$ & $\begin{array}{c}575 \\
427 \\
107 \\
19 \\
22\end{array}$ & $\begin{array}{l}3,6 * * * \\
3,5 * \\
4,7 \\
-3,0 \\
4,0\end{array}$ \\
\hline $\begin{array}{l}\text { Não ocupados } \\
\text { Desempregado } \\
\text { Outros }\end{array}$ & $\begin{array}{l}1224 \\
37 \\
1187\end{array}$ & $\begin{array}{c}1168 \\
37 \\
1131\end{array}$ & $\begin{array}{c}1137 \\
43 \\
1094\end{array}$ & $\begin{array}{c}1207 \\
49 \\
1157\end{array}$ & $\begin{array}{l}-0,7 \\
10,7 \\
-1,1\end{array}$ \\
\hline Total & 3551 & 3571 & 3525 & 3612 & 0,4 \\
\hline
\end{tabular}

(*) PEA restrita: exclui pessoas com menos de $15 \mathrm{~h}$ de ocupação e exclusivamente dedicadas à autoconstrução e à produção para o autoconsumo. a) estimativa do coeficiente de uma regressão log-linear contra o tempo. Nesse caso, o teste t indica a existência

ou não de uma tendência nos dados. ${ }^{* * *},{ }^{* *}$, * significam respectivamente $5 \%, 10 \%$ e $20 \%$.

Fonte: PNAD/IBGE - Tabulações Especiais dó Projeto Rurbano - Elaboração própria.

\section{A dialética da pluriatividade}

O novo ambiente macroeconômico (2001-2004) menos adverso para os produtores agrícolas de um modo geral - comparativamente aos anos 1990 - e, mais do que isso, favorável aos agricultores em vários aspectos (melhoria dos preços internacionais, câmbio desvalorizado para os patamares dos anos 90 etc.), resultou em elevação da PEA agrícola assalariada. Isso provavelmente explica o crescimento das famílias de conta-próprias pluriativas tradicionais. Fora isso, os dados apontam para a continuidade do não crescimento da pluriatividade total e, especialmente, da pluriatividade intersetorial sulinas - a despeito da melhora das condições adversas que predominaram na década de 1990. A novidade desse período menor é que a pluriatividade sulina não mais declinou, como aconteceu na década anterior. Ou seja, estabilizou-se, do ponto de vista estatístico.

Essa estabilidade só é bem entendida quando se considera a lógica interna de funcionamento da agricultura moderna sulina, conjugada com as transformações econômicas dos anos 90 e a reação dos agricultores a essas transformações.

Procuramos ressaltar, no que se refere à questão da evolução da pluriatividade na região Sul, um aspecto central contido na modernização agrícola: possibilita, por um lado, liberar força de trabalho no interior de uma certa parcela das unidades familiares agrícolas para se ocupar em outros setores da economia, provocando, dessa forma, como resultante do processo, a proliferação de casos de famílias pluriativas; mas que, por outro turno, não oferece espaço, simultaneamente, para todos os produtores familiares. Isso significa que, em um determinado horizonte de tempo do desenvolvimento das forças produtivas capitalistas no interior da agricultura, cada vez menos produtores familiares lograrão permanecer participando da dinâmica do hard core dos circuitos produtivos e de comercialização.

Como já tivemos oportunidade de argumentar em outro momento deste tex- 
to, esse processo não implica um automático e inexorável abandono do setor pelas famílias pluriativas e agrícolas “ineficientes”, seguido de sua conversão em famílias não agrícolas. Essa é uma questão que dependerá do grau de dinamismo econômico dos entornos rurais (economias locais). Para os produtores familiares descapitalizados e incapacitados de competir por um espaço no mercado, se o entorno rural (redes urbanas) que os envolve for dinâmico do ponto de vista não agrícola, pode-se supor, então, haver uma plausível tendência de parte dessas famílias tornar-se famílias não agrícolas (essa é a explicação que damos para o caso da região Sul, notadamente nos anos 90). ${ }^{15}$

Trata-se, portanto, de um processo, cuja contradição, interna, desnuda-se visivelmente nos momentos de crise do setor. Ou seja, em tais momentos acirrase a luta entre os diferentes capitais privados individuais por fatias do mercado - como é o caso dos anos 90 no Brasil, influenciado pela abertura comercial e pelo câmbio valorizado, exacerbando a concorrência externa -, cuja resultante é o aumento da produtividade daquelas unidades com maior capacidade de reação ao novo ambiente econômico adverso - e, por meio desse processo, possibilita-se, em tese, a criação de mais casos de pluriatividade no interior das unidades familiares agora mais produtivas. Porém, a outra face do mesmo processo refere-se ao ajuste estrutural das unidades produtivas em que aquelas que não lograram adaptar-se às novas condições de concorrência, ou aceitarão permanecer no setor, marginalizadas do processo e com rendimentos da exploração inferiores ao que obtinham em outra situação, ou abandonarão de vez o mesmo - e, entre estas, podem estar muitas famílias pluriativas que deixarão de sê-lo. ${ }^{16}$

Isso não significa que, de outro modo, nas conjunturas mais favoráveis ao setor - como é o caso do quadriênio que estamos tratando nesta seção (20012004) - a mencionada contradição deixe de existir. Na verdade, ela sempre estará presente, mantidas as condições predominantes (organização do setor por critérios privados de eficiência etc.), especialmente numa economia globalizada como a brasileira. O que ocorre é que uma conjuntura favorável atenua a força interna da referida contradição, de modo que uma parcela mais larga dos produtores familiares se beneficia do ambiente menos conflitivo.

Portanto, a explicação da relativa estabilidade da pluriatividade e do conjunto da agricultura familiar na região Sul, no período 2001-2004, passa por esta análise. Dois elementos conjugados entre si contribuem para essa estabilidade.

\footnotetext{
${ }^{15}$ No Nordeste, ao contrário do Sul, é a combinação entre entorno rural pobre e predomínio de uma agricultura tecnologicamente atrasada que faz com que cresça o número de famílias pluriativas intersetoriais - porque nenhuma das duas atividades substitui a outra, uma vez que ambas são precárias; isso faz com que as famílias agrícolas pobres se tornem pluriativas fazendo "bicos", reagindo à condição de pobreza (Nascimento, 2005b).

${ }^{16}$ Carneiro (1996) trata da pluriatividade na França, não considerando esse outro lado, restringindose ao efeito da liberação da mão-de-obra familiar para se ocupar em outros setores.
} 
Ambos se complementam. O primeiro diz respeito à inflexão no regime cambial a partir de 1999, revertendo o impacto negativo que o regime anterior provocava sobre o desempenho da agricultura, passando a funcionar como uma proteção, contra a concorrência, para um leque maior de produtores familiares. O segundo elemento concerne ao efeito resultante do processo de ajustamento da estrutura produtiva agrícola (anos 90), tornando-a mais eficiente à medida que selecionou os mais capazes a permanecerem na disputa no mercado (mais globalizado). O efeito resultante desse ajuste estrutural das unidades produtivas na região Sul possui o significado de que o conjunto de produtores rurais que foram selecionados (que puderam se proteger) durante a crise dos anos 90, iniciou a presente década com mais possibilidades de preservação da sua capacidade de reprodução social. Alia-se a essa condição estrutural a conjuntura macroeconômica mais favorável (o primeiro elemento), que não está exercendo pressão, pelo menos não na mesma intensidade exercida nos anos 90 , por novos ajustes na estrutura produtiva do setor, traduzindo-se em uma menor pressão à (tendência de) expulsão de mais agricultores do setor.

Assim, consideramos plausível supor que, dada a permanência latente da referida contradição no interior da agricultura moderna disseminada na região Sul, alterações nas condições macroeconômicas poderão acirrar esse movimento contraditório, e novamente os microdados da PNAD podem vir a registrar a continuidade do processo de redução da base familiar (particularmente, das famílias pluriativas) de produção agrícola sulina.

\section{CONSIDERAÇÕES FINAIS}

A pluriatividade é uma temática importada, como tantas outras, de realidades bem diferentes da brasileira. Por essa razão, merece ser tratada, no caso da região Sul, considerando a especificidade do modelo agrícola dessa região, conjugada à política agrícola do país. Tanto na UE como no Brasil a política agrícola beneficia grandes produtores; mas, no primeiro caso, existe um conteúdo social voltado para pequenos produtores que é decisivo para alicerçar a trajetória de crescimento da pluriatividade (Nascimento, 2005a). É justamente a aguda precariedade desse elemento no caso brasileiro que impede a pluriatividade de crescer no Sul - cujas características essenciais foram enfatizadas ao longo do texto.

Concordamos com a análise de que os processos de industrialização difusa ocorridos no interior da região Sul - anteriormente aos anos 1980 - convergiram, em combinação com as características da agricultura camponesa da região, para a proliferação de casos de pluriatividade (Sacco dos Anjos, 1994; Schneider, 1999). Contudo, as informações fornecidas no presente trabalho nos levam a crer que as próprias condições econômicas criadas pela industrialização difusa, no tocante às redes urbanas da região, juntamente com o efeito do aprofundamento da modernização da agricultura dessa região (seguindo critérios de mercado e 
sem uma ampla ação das políticas públicas compensando os pequenos produtores "ineficientes"), não mais conduzem as famílias rurais a se tornarem pluriativas, senão a se tornarem progressivamente famílias rurais não agrícolas. ${ }^{17}$

Enfim, para a pluriatividade crescer no Sul do Brasil e poder acompanhar o crescimento dos problemas que ela deveria enfrentar, defendemos a necessidade de uma abrangência bem maior dos programas de políticas públicas (o que caberia, por exemplo, ao PRONAF) de modo a atender muito mais pequenos produtores familiares do que se atende na atualidade. Ou seja, a relevância dessas considerações todas reside em que, se a sociedade brasileira considerar importante elaborar políticas para promover de maneira sustentável mais casos de pluriatividade, a fim de esta servir de instrumento para combater o desemprego rural e urbano (segurando a população rural em seu local de origem, com algum vínculo a uma atividade agrícola), não será apenas fomentando atividades não agrícolas que aquele objetivo será alcançado. Poderá resultar simplesmente em mais crescimento de famílias não agrícolas - não que esse resultado não seja desejável; pelo contrário, uma vez que essa também poderá vir a ser perfeitamente outra alternativa da sociedade para a resolução dos problemas contemporâneos. Contudo, a questão aqui é: se a sociedade quiser apostar em um crescimento da pluriatividade como uma das formas de enfrentamento do desemprego rural e de desafogo das cidades, tem-se que compensar a vastidão de pequenos produtores familiares dos efeitos adversos provocados pela agricultura moderna regida por critérios de mercado - evitando seu paulatino abandono das atividades agrícolas "tradicionais" - , além de lhes proporcionar mais oportunidades ocupacionais não agrícolas. Trata-se, portanto, de uma questão claramente, a priori, de cunho politico.

\section{REFERÊNCIAS BIBLIOGRÁFICAS}

ALVES, E. (2001). "Quem ganhou e quem perdeu com a modernização da agricultura brasileira”. Revista de Economia e Sociologia Rural 39 (3): 09-40.

ALVES, E. R. A.; SOUZA, D. P. H. (2000) "Produção brasileira de leite”. Economia Rural. Viçosa, MG, 11 (1): 16-30.

AQUINO, J. R.; TEIXEIRA, O. A.; TONNEAU, J. (2004) “Pronaf: política agrícola discriminatória?” IX Encontro Nacional de Economia Política — ENEP. Uberlândia, MG.

ARKLETON TRUST (1992). “Adaptation des menages agricoles en Europe Occidentale 1987-1991

- Rapport final du programme de recherche sur les structures et la pluriactivite des menages agricoles”. Luxembourg, Commission Européenne.

BITTENCOURT, G. A. (2003) "Abrindo a caixa preta: o financiamento da agricultura familiar no Brasil”. Campinas, SP: Unicamp, 2003. (dissertação de mestrado)

BRANDÃO, A. S. P.; REZENDE, G. C.; MARQUES, R. W. C. (2005) “Crescimento agrícola no Bra-

${ }^{17} \mathrm{E}$ isso não se deve a uma questão de "ciclo de vida" chayanoviano, já que as famílias sulinas pluriativas que deixaram de sê-lo nos anos 1990, deveriam ter voltado a ser famílias agrícolas; mas como se pôde ver (Tabelas 4 e 5), estas também diminuíram 
sil no período 1999-2004: explosão da soja e da pecuária bovina e seu impacto sobre o meio ambiente". Texto para Discussão, n. 1103. Rio de Janeiro: IPEA.

CAMPANHOLA, C.; GRAZIANO DA SILVA, J. (orgs.). O novo rural brasileiro. Brasília: Embrapa, 7 volumes, 2000.

CARNEIRO, M. J. (1996) "Pluriatividade no campo: o caso francês". Revista Brasileira de Ciências Sociais 32, ano 11: 89-104.

GASQUES, J. G.; SPOLADOR, H. F. S. (2003) “Taxa de juros e política de apoio interno à agricultura". Texto para Discussão, n. 952. IPEA: Brasília.

GOULARTI FILHO, A. (2001) "Padrões de crescimento e diferenciação econômica em Santa Catarina”. Campinas: IE/UNICAMP. (tese de doutoramento).

GRUPO DE BRUGGE (1996). Por um cambio necessário em la agricultura europea. Córdoba (Espanha), IESA, 1996.

HELFAND, S. M.; REZENDE, G. C. (2001) "Agricultura brasileira nos anos 90: o impacto das reformas de políticas”. In GASQUES, J. G.; CONCEIÇÃO, J. C. P. R. (orgs.). Transformações da agricultura e políticas públicas. Brasília: IPEA, 2001, p. 539.

HOMEM DE MELO, F. “Liberalização comercial e agricultura familiar no Brasil”. In Comércio Internacional, Segurança Alimentar e Agricultura Familiar. Brasil - REBRIP, Action Aid Brasil, p.7-44, 2001.

MDA/INCRA/FAO. Novo retrato da agricultura familiar — o Brasil redescoberto. Brasília, 2000.

NASCIMENTO, C. A. "A política agrícola comum da CEE e a ocupação das famílias rurais em atividades agrícolas e não-agrícolas: lições para a política agrícola no Brasil”. Economia e Sociedade, 14 (2): 263-285, 2005a.

"Pluriatividade, pobreza rural e políticas públicas". Campinas, SP: IE/Unicamp. 2005b (Tese de doutoramento)

SACCO DOS ANJOS, F. Agricultura familiar, pluriatividade e desenvolvimento rural no Sul do Brasil. Pelotas: EGUFPEL, 2003.

A Agricultura Familiar em Transformação: o caso dos colonos-operários da Massaranduba. Pelotas, SC: Editora da UFPEL, 1994.

SCHNEIDER, S. Pluriatividade na Agricultura Familiar. Porto Alegre: Editora da UFRGS, 2003. Agricultura familiar e industrialização: pluriatividade e descentralização industrial no Rio Grande do Sul. Porto Alegre: Editora da UFRGS, 1999.

SCHNEIDER, S.; NAVARRO, Z. "Emprego agrícola e novas formas de ocupação no Rio Grande do Sul”. In CAMPANHOLA, C.; GRAZIANO DA SILVA, J. (orgs.) op. cit., v.3, 2000.

TOLOSANA, A. O.; PERSIVA, E. M. "Estratégia de adaptacion de pequeñas explotaciones en el marco de la PAC. La agricultura a tiempo parcial em um área de montana”. Revista de Estudios Agro-Sociales, n. 16,: 99-122, 1992. 